\title{
REVIEW
}

\section{Epidemiological evidence of effects of coarse airborne particles on health}

\author{
B. Brunekreef* and B. Forsberg ${ }^{\#}$
}

ABSTRACT: Studies on health effects of airborne particulate matter (PM) have traditionally focused on particles $<10 \mu \mathrm{m}$ in diameter (PM10) or particles $<2.5 \mu \mathrm{m}$ in diameter (PM2.5). The coarse fraction of $\mathrm{PM} 10$, particles $>2.5 \mu \mathrm{m}$, has only been studied recently. These particles have different sources and composition compared with PM2.5. This paper is based on a systematic review of studies that have analysed fine and coarse PM jointly and examines the epidemiological evidence for effects of coarse particles on health.

Time series studies relating ambient PM to mortality have in some places provided evidence of an independent effect of coarse PM on daily mortality, but in most urban areas, the evidence is stronger for fine particles. The few long-term studies of effects of coarse PM on survival do not provide any evidence of association.

In studies of chronic obstructive pulmonary disease, asthma and respiratory admissions, coarse PM has a stronger or as strong short-term effect as fine PM, suggesting that coarse PM may lead to adverse responses in the lungs triggering processes leading to hospital admissions. There is also support for an association between coarse PM and cardiovascular admissions.

It is concluded that special consideration should be given to studying and regulating coarse particles separately from fine particles.

KEYWORDS: Air pollution, coarse particles, epidemiology, morbidity, mortality

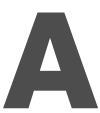

irborne particles come in all sorts of sizes, shapes and compositions. The smallest, "ultrafine" particles are generated by nucleation and condensation, largely from combustion emissions. Their numbers are large (easily $>10,000$ per cc), their mass is small (mass concentration usually reaches only a few $\mu \mathrm{g} \cdot \mathrm{m}^{-3}$ ). Ultrafine particles are inherently unstable, and grow through coagulation and condensation to larger "accumulation" particles, which are mostly $0.1-1 \mu \mathrm{m}$ in diameter. These particles usually make up more than half of the particle mass in ambient air. Sulphates, nitrates, and elemental and organic carbon often dominate their composition. Because combustion processes ultimately generate all of these, such particles are usually coined "combustion" particles. Particles $>1-2 \mu \mathrm{m}$ usually have a quite different origin and composition. They are generated primarily by mechanical processes, such as wind or abrasion. Often, crustal material, such as silicates, is a large fraction of coarse particles but this depends on the specific sources: metals may be

For editorial comments see page 187. important when large metallurgic industries are a main source. Such coarse particles may vary in size all the way up to $100 \mu \mathrm{m}$, larger particles become too heavy to remain airborne for any length of time.

In the last 15 yrs, airborne particles have been characterised in many areas by measurement of particulate matter $(\mathrm{PM})<10 \mu \mathrm{m}$ in diameter (PM10), because particles of this size can penetrate into the thoracic part of the airways where they may have adverse effects. The more inclusive measure of total suspended particulates (TSP) did incorporate larger particles, but was considered to be too unspecific to be used as a basis for air quality standards aimed at protecting human health. Effectively, introduction of PM10 has removed the larger particles, which may still deposit in the upper airways (nose, throat) from consideration when studying and regulating health effects of particles. Because PM10 is often mostly consisting of particles smaller than a few micrometres, it cannot be easily distinguished in studies from fine particles (FP), often measured as particles $<2.5 \mu \mathrm{m}$ or PM2.5. That is not to say that the concentrations
AFFILIATIONS

*Institute for Risk Assessment

Sciences, Utrecht University, Utrecht, The Netherlands.

\# Dept of Public Health and Clinical Medicine, Umea University, Umea, Sweden.

CORRESPONDENCE

B. Brunekreef

Institute for Risk Assessment

Sciences

Utrecht University

P0 Box 80176

3508 TD Utrecht

The Netherlands

Fax: 31302539499

E-mail: b.brunekreef@iras.uu.n

Received:

January 062005

Accepted after revision:

May 132005

\section{SUPPORT STATEMENT}

B. Forsberg was supported by the Swedish Environmental Protection Agency. B. Brunekreef conducted this work partly in conjunction with his responsibilities as member of the Scientific Advisory Committee of the WHO "Systematic Review of Health Aspects of Air Pollution in Europe" (2002-2004). 
are the same; the issue is that temporal and spatial variation of PM2.5 and PM10 are often similar, despite the difference in sources and composition between fine and coarse particles $(\mathrm{CP})$, simply because PM2.5 is such a large fraction of PM10.

Only in recent years has the difference between coarse and fine particles come to be more explicitly appreciated. Investigators have included separate measurements of fine and coarse particles in their studies rather than measurements of PM2.5 and PM10. This has shown that, in contrast to the high correlation between PM10 and PM2.5, there is often much less correlation between PM2.5 and coarse particles, usually defined and measured as particles $>2.5$ and $<10 \mu \mathrm{m}$. Of note is that sometimes this quantity is arrived at by subtracting a direct measurement of PM2.5 from a direct measurement of PM10; the disadvantage of this is that coarse particle measurement is then affected by two measurement errors rather than one. Other sampling configurations separate fine and coarse particles before they are collected on filters to be weighed, or are detected by other means.

These recent studies have made it possible to investigate the role of fine and coarse particles without running into the complication that any statement about PM10 is likely to be also valid for (or even dominated by) PM2.5, simply because PM2.5 is such a large fraction of PM10. The observation that the correlation between fine and coarse particles if often low has made it relatively easy to separate their effects in field studies. Separate collection of fine and coarse particles on appropriate media has also facilitated toxicology studies, allowing conclusions as to whether, on a mass basis, the two fractions have equal or different toxicities, qualitatively as well as quantitatively.

A detailed description of the occurrence, measurement and correlations of coarse and fine particles can be found in WILSON and Su [1]. These authors concluded that "fine and coarse particles are separate classes of pollutants and should be measured separately in research and epidemiologic studies. PM2.5 and PM(10-2.5) are indicators or surrogates, but not measurements, of fine particles." To illustrate the last point, it has been shown that in certain areas windblown dust significantly contributes to PM2.5 [2].

An early example of a study that addressed fine and coarse PM separately is a study from the USA [3,4] which found that daily mortality in six cities was associated with fine particles but not with coarse particles. Since then, a small body of evidence has emerged that allows further analysis of the relative importance of fine and coarse particles.

\section{AIM AND METHODS}

This paper reviews what is known from epidemiological studies about the health effects of coarse particles. As there are virtually no studies that have defined "coarse particles" other than PM10-2.5 (occasionally PM15-2.5), what is know about "coarse PM mass" or CM refers to particles $<10$ (or 15) $\mu \mathrm{m}$, and $>2.5 \mu \mathrm{m}$. The emphasis is on comparing effect estimates for fine and coarse particles within studies, and the aim of this Review was to include all time-series studies giving coefficients for both fractions. Papers were selected through a systematic search in PubMed and the time-series database Air Pollution Epidemiology Database (APED) at St. George's Hospital Medical School, London University, used in a recent meta-analysis for the World Health Organization [5]. This paper addresses the question whether there is evidence in time series studies of an effect of coarse particles on daily mortality and morbidity. As measurement error may depend on the method of measurement of coarse particles (i.e. by direct measurement or by subtraction of measured PM2.5 from measured PM10), it has been indicated in the tables which method was used. Most studies report several effect estimates for both metrics; in this Review one or a few have been chosen to be representative of the study, ensuring that the effect estimates for coarse and fine PM were from a strictly comparable set of data within the studies. Several studies have recently been re-analysed after new insights into modelling of time series data emerged; if so, effect estimates from the re-analysed data have been chosen as reported in a monograph published by the Health Effects Institute [6]. Few studies have presented results of analyses in which fine and coarse PM were jointly analysed. The results of two-pollutant models have been addressed whenever they were available. The data on coarse PM effects are currently too sparse to permit a formal meta-analysis of the results.

\section{EFFECTS OF COARSE PARTICLES ON SHORT-TERM MORTALITY}

The results of time series studies on effects of fine and coarse particles on mortality are summarised in table 1 [3, 4, 7-22]. The table includes the reported correlations between fine and coarse particles, which were typically around or somewhat $<0.5$. In all reported studies, correlations between PM10 and coarse, as well as fine, particles were much higher (as both fine and coarse particles are part of PM10).

There were four studies that not only reported separate estimates for fine and coarse PM, but also the results of a two-pollutant analysis [7, 9-12, 14]. The first three found that effects of coarse PM were no longer there after adjustment for fine PM, whereas the fine PM effects remained. No twopollutant analyses have been published for the Canadian data $[9,10]$ but they have been conducted, and they show that the fine PM effect persisted, but that the coarse PM effect was attenuated and nonsignificant (R. Burnett, Biostatistics and Epidemiology Division, Safe Environments Directorate, Healthy Environments and Consumer Safety Branch, Health Canada, Ottawa, Canada, personal communication). The effect estimates in the table are from the recent re-analysis report [9]. Only a study from Mexico City [14] found the opposite result. The authors speculated that there was much biogenic contamination in the coarse mass fraction in Mexico City.

Of the studies reporting only single pollutant analyses, the original SCHWARTZ et al. [3] study conducted in six USA cities, replicated by KLEMM et al. [4] is still the study with the largest number of observations, some 190,000 deaths observed over a number of years. In this study, fine PM was associated with mortality but coarse PM was not. Of interest is that in the one town where $\mathrm{CP}$ was found to be associated with mortality (Steubenville), the correlation between FP and CP was high at 0.69. Another study from Philadelphia found associations between mortality and fine and coarse PM of roughly similar magnitude, although the associations with $\mathrm{CM}$ were mostly not significant [8]. The Environmental Protection Agency (EPA) PM criteria document has calculated effect estimates 
TABLE 1 Summary of time series studies relating fine and coarse particulate matter to mortality

\begin{tabular}{|c|c|c|c|c|c|c|}
\hline [7] & Santiago, Chile & 186000 & Direct & 0.52 & $\begin{array}{l}\text { FP: } 0.7(0.5-0.9) \\
\text { CP: } 0.9(0.6-1.3)\end{array}$ & $\begin{array}{l}\text { FP: } 0.7(0.4-1.0) \\
\text { CP: } 0.1(-0.3-0.5)\end{array}$ \\
\hline$[9,10]$ & $\begin{array}{l}\text { Eight Canadian } \\
\text { cities }\end{array}$ & 110000 & Direct & 0.37 & $\begin{array}{l}\text { FP: } 1.4(0.5-2.3) \\
\text { CP: } 0.8(0.0-1.6)\end{array}$ & $\begin{array}{l}\text { FP effect remains significant, } \\
\text { CP effect no longer }\end{array}$ \\
\hline$[11,12]$ & $\begin{array}{c}\text { Santa Clara County, } \\
\text { USA }\end{array}$ & 60000 & Direct & 0.51 & $\begin{array}{l}\text { FP: } 2.9(0.6-5.3) \\
\text { CP: } 1.3(-2.2-4.9)\end{array}$ & $\begin{array}{l}\text { FP } 3.5(0.7-6.6) \\
\text { CP -2.4 (-9.0-4.8) }\end{array}$ \\
\hline [13] & West Midlands, UK & 49000 & Direct & 0.34 & $\begin{array}{c}\text { FP: } 0.3(-0.8-1.5) \\
\text { CP: }-0.5(-3.8-2.0)\end{array}$ & NA \\
\hline$[16,17]$ & $\begin{array}{l}\text { Detroit/Michigan } \\
\text { County, USA }\end{array}$ & 25000 & Direct & 0.42 & $\begin{array}{l}\text { FP: } 0.8(-0.6-2.4) \\
\text { CP: } 1.1(-0.9-3.3)\end{array}$ & NA \\
\hline$[18,19]$ & $\begin{array}{c}\text { Coachella Valley, } \\
\text { USA }\end{array}$ & 21000 & Indirect & $0.28-0.46$ & $\begin{array}{r}\text { Total: FP: } 4.4 \text { (0.0-8.9) } \\
\text { CP: } 0.5(-0.5-1.0) \\
\text { CVD:FP: } 3.3(-2.2-10.0) \\
\text { CP: } 1.0(0.5-2.0)\end{array}$ & NA \\
\hline
\end{tabular}

R: Pearson correlation coefficient; PM10: particles <10 $\mu \mathrm{m}$ in diameter; PM2.5: particles <2.5 $\mu \mathrm{m}$ in diameter; FP: fine particles; CP: coarse particles; CVD: cardiovascular disease; Resp: respiratory; NA: not available.

that are in the order of a $1.6 \%$ increase in cardiovascular mortality per $10 \mu \mathrm{g} \cdot \mathrm{m}^{-3}$ for both metrics, being significant for fine but not for coarse PM [23].

A number of studies found no evidence of effects of either PM metric on mortality $[13,15-17,20]$

In a study conducted in the arid Coachella Valley, California, OsTRO et al. [18] found evidence for effects of fine particles (but not coarse particles) on total mortality. When the analysis was restricted to cardiovascular mortality, there was a significant association with coarse but not fine particles, although the effect estimate for fine particles was still much larger than for coarse PM. The results were generally unaffected by model specification [19]. In the re-analysis published in 2003, the authors looked at cardiovascular mortality only, so that no comparison is possible with the original report with respect to total mortality.

In a small study from Phoenix, Arizona, USA, where coarse $\mathrm{PM}$ is higher than fine PM due to arid conditions, both were found to be associated with cardiovascular mortality at lag 0 . At lag 1 the association was stronger for fine $(7.1 \%$ per 10 $\mu \mathrm{g} \cdot \mathrm{m}^{-3}, 95 \%$ confidence interval (CI) $1.1-12.9 \%$ ) than for coarse particles $\left(1.6 \%\right.$ per $\left.10 \mu \mathrm{g} \cdot \mathrm{m}^{-3}, 95 \% \mathrm{CI}-0.5-3.8 \%\right)$ [21, 22]. In Santiago coarse PM were more important than FP in summer [7].

A graphical illustration of the effect estimates for coarse and fine PM on mortality is shown in figure 1.

\section{EFFECTS OF COARSE PARTICLES ON LONG-TERM MORTALITY}

The largest cohort study conducted in the USA found no evidence that coarse PM was associated with mortality over long periods of follow-up, showing an essentially zero effect estimate for total mortality [23]. The Six Cities Study [24] as quoted by USA EPA in the final Criteria Document for Particulate Matter also did not find a significant relationship between coarse particles (defined as PM15-2.5) and mortality after 14 yrs of follow-up (concentration range 9.7, relative risk 


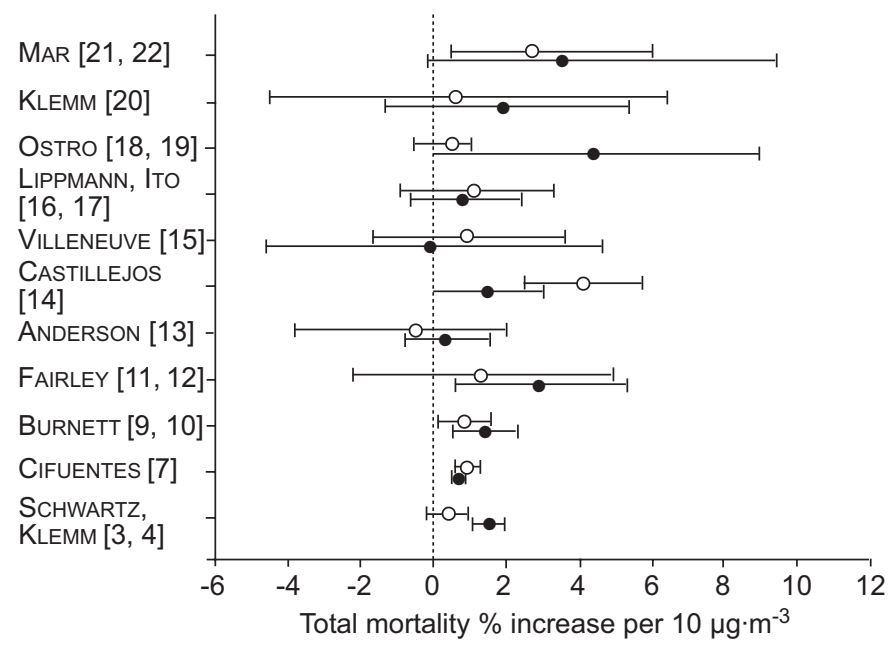

FIGURE 1. Effect of fine published time series studies.
1.19 (0.91-1.55) [25]. This is an important observation because (proposals for) annual average limit values for fine PM rely in part on the results of these cohort studies.

\section{EFFECTS OF COARSE PARTICLES ON SHORT-TERM MEASURES OF MORBIDITY}

Eleven papers presenting studies of associations with hospital admissions for respiratory and cardiovascular disease [13, 16, 26-32, 33, 34] and three studies of emergency department visits [35-37] were identified (table 2). Five of these studies are from Toronto, Canada [26, 27, 29, 31, 32], but have used different outcomes, study populations and particle exposure metrics. In the longer studies of cardiorespiratory admissions [29] and respiratory admissions in children [31, 32] in 1980-1994, the coarse and fine fractions were estimated from TSP and sulphate. These studies indicate that the coarse fraction may be more important $[27,31,32]$ or at least a stronger predictor for some endpoints than is the fine fraction [29]. The coarse fraction, in particular, had a strong effect on total CVD admissions in all ages, $\sim 8 \%$ per $10 \mu \mathrm{g} \cdot \mathrm{m}^{-3}$ in single pollutants models [27]. However, PM metrics in these Canadian studies

TABLE 2 Summary of time series studies relating fine and coarse particulate matter to hospital admissions

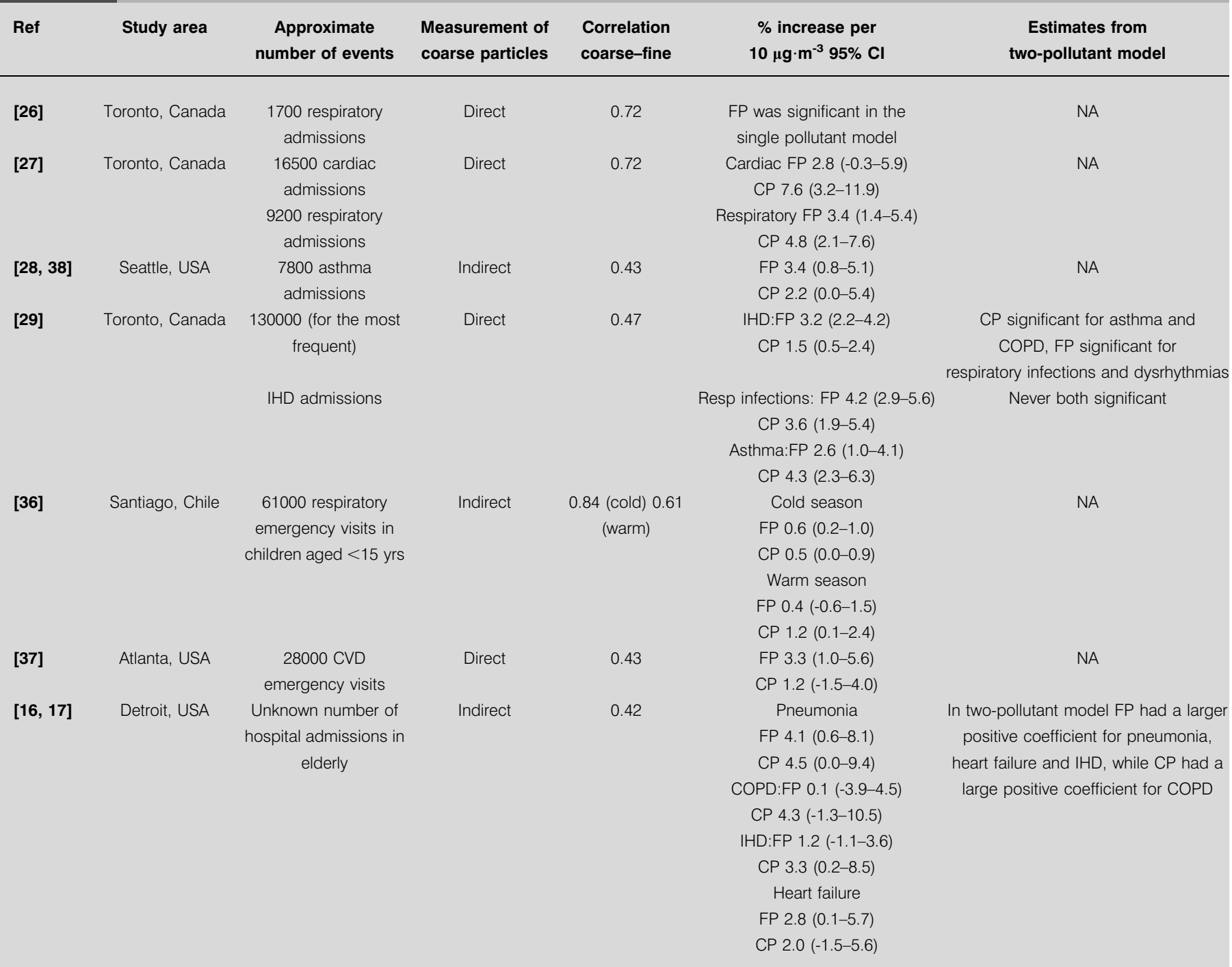


TABLE 2 Continued

\begin{tabular}{|c|c|c|c|c|c|c|}
\hline Ref & Study area & $\begin{array}{c}\text { Approximate } \\
\text { number of events }\end{array}$ & $\begin{array}{l}\text { Measurement of } \\
\text { coarse particles }\end{array}$ & $\begin{array}{l}\text { Correlation } \\
\text { coarse-fine }\end{array}$ & $\begin{array}{c}\% \text { increase per } \\
10 \mu \mathrm{g} \cdot \mathrm{m}^{-3} 95 \% \mathrm{Cl}\end{array}$ & $\begin{array}{l}\text { Estimates from } \\
\text { two-pollutant model }\end{array}$ \\
\hline [30] & $\begin{array}{c}\text { Los Angeles county, } \\
\text { USA }\end{array}$ & $\begin{array}{l}11000 \text { hospital } \\
\text { admissions for COPD }\end{array}$ & Indirect & & $\begin{array}{l}\text { COPD aged }>65 \text { yrs } \\
\text { FP } 2.0(0.4-3.6) \\
\text { CP } 2.0(-0.2-4.2) \\
\text { COPD aged 20-64 yrs } \\
\text { FP } 1.7(0.1-3.3) \\
\text { CP } 2.4(-0.1-4.9) \\
\text { COPD aged 0-19 yrs } \\
\text { FP } 0.6(-1.8-3.0) \\
\text { CP } 6.6(3.2-10.0)\end{array}$ & NA \\
\hline [13] & $\begin{array}{l}\text { West Midlands } \\
\text { conurbation, UK }\end{array}$ & $\begin{array}{c}47000 \text { CVD } \\
\text { admissions } \\
44000 \text { respiratory } \\
\text { admissions }\end{array}$ & Indirect & 0.34 & $\begin{array}{l}\text { CVD:FP -0.3 (-1.5-0.9) } \\
\text { CP -0.6 }(-3.3-11.9) \\
\text { Resp:FP } 0.7(-0.5-1.4) \\
\text { CP } 0.2(-2.2-2.7)\end{array}$ & NA \\
\hline [32] & Toronto, Canada & $\begin{array}{l}7300 \text { asthma } \\
\text { admissions in children } \\
\text { aged } 6-12 \text { yrs }\end{array}$ & Direct & 0.44 & $\begin{array}{l}\text { Young males } \\
\text { FP -4.3 (-10.8-1.1) } \\
\text { CP 11.8 (3.6-21.3) } \\
\text { Young females } \\
\text { FP } 5.4(-3.2-12.9) \\
\text { CP } 21.3(9.5-35.5)\end{array}$ & NA \\
\hline [34] & Vancouver, Canada & $\begin{array}{l}4400 \text { hospital admis- } \\
\text { sion for COPD }\end{array}$ & Indirect & Moderate & $\begin{array}{l}\text { FP } 19.8(4.0-36.5) \\
\text { CP } 21.2(6.0-37.6)\end{array}$ & $\begin{array}{l}\text { FP } 15.5(-0.2-34.3) \\
\text { CP } 15.9(-0.1-32.6)\end{array}$ \\
\hline [35] & Spokane, USA & $\begin{array}{l}29000 \text { respiratory } \\
\text { emergency visits }\end{array}$ & Indirect & 0.31 & $\begin{array}{l}\text { FP } 2.0(-1.0-5.0) \\
\text { CP } 0.8(-0.4-2.0)\end{array}$ & NA \\
\hline [33] & Atlanta, USA & $\begin{array}{c}27000 \text { CVD } \\
\text { emergency visits }\end{array}$ & Direct & 0.43 & $\begin{array}{l}\text { FP } 3.3(1.0-5.6) \\
\text { CP } 2.4(-3.0-8.0)\end{array}$ & NA \\
\hline
\end{tabular}

95\% Cl: 95\% confidence interval; IHD: ischaemic heart disease; CVD: cardiovascular disease; COPD: chronic obstructive pulmonary disease; FP: fine particles; CP coarse particles; Resp: respiratory; NA: not applicable.

tended to be sensitive for inclusion of gaseous pollutants in two-pollutant models, although more so for PM2.5 than for coarse particles [27]. With levels of coarse and fine particles estimated from TSP and sulphate, there was less support for an effect on CVD admissions [29].

Various categories of CVD hospital admissions among the elderly in Detroit were positively associated with fine and coarse particles (and other pollutants), in some cases significantly. The associations were rather robust when co-pollutants were included in the models [16]. It was not possible, either from the original analysis or the re-analysis, to conclude that any fraction was more important than the other. The strongest effects of the coarse fraction reached $\sim 4 \%$ per $10 \mu \mathrm{g} \cdot \mathrm{m}^{-3}$ for IHD admissions in the elderly.

The coarse fraction is a better predictor of the daily numbers in several studies of asthma, chronic obstructive pulmonary disease (COPD) and/or all respiratory admissions [16, 29$32]$, while the effect of fine and coarse particles on asthma was more similar in some cases [28,34-36]. In general there was an increase in admissions of $2-6 \%$ per $\%$ per $10 \mu \mathrm{g} \cdot \mathrm{m}^{-3}$ for respiratory admissions. The highest effect-size estimates for the coarse fraction exceed $10 \%$ per $10 \mu \mathrm{g} \cdot \mathrm{m}^{-3}$, particularly with longer averaging times [32]. In a study from Chile, there were inconsistent results for different diagnoses and seasons [36]. Three of the diagnosis-season combinations showed the strongest association for FP and three for CP. In one of the studies from Toronto, only $\mathrm{CP}$ displayed at least a marginal level of evidence of an association after adjustment for copollutants [27]. Graphical illustration of the effects of fine and coarse particles on respiratory, COPD and cardiovascular admissions is shown in figures $2-4$.

\section{EFFECTS OF DUST STORMS AND WIND-BLOWN DUST}

SCHWARTZ et al. [39] analysed a time series of mortality data from Spokane, Washington, USA where dust storms regularly occur. The authors found that on dust storm days, which had an average PM10 concentration of $263 \mu \mathrm{g} \cdot \mathrm{m}^{-3}$, there was no increased mortality compared with control days, which had an average PM10 concentration of $42 \mu \mathrm{g} \cdot \mathrm{m}^{-3}$.

A study of respiratory hospital admissions from Washington State, USA [40] found an association with PM10. This association was not significantly smaller in the fall period when PM10 was suggested to be dominated by wind-blown dust. One would expect a smaller association if wind-blown dust was innocuous. A study from Anchorage, USA, where 


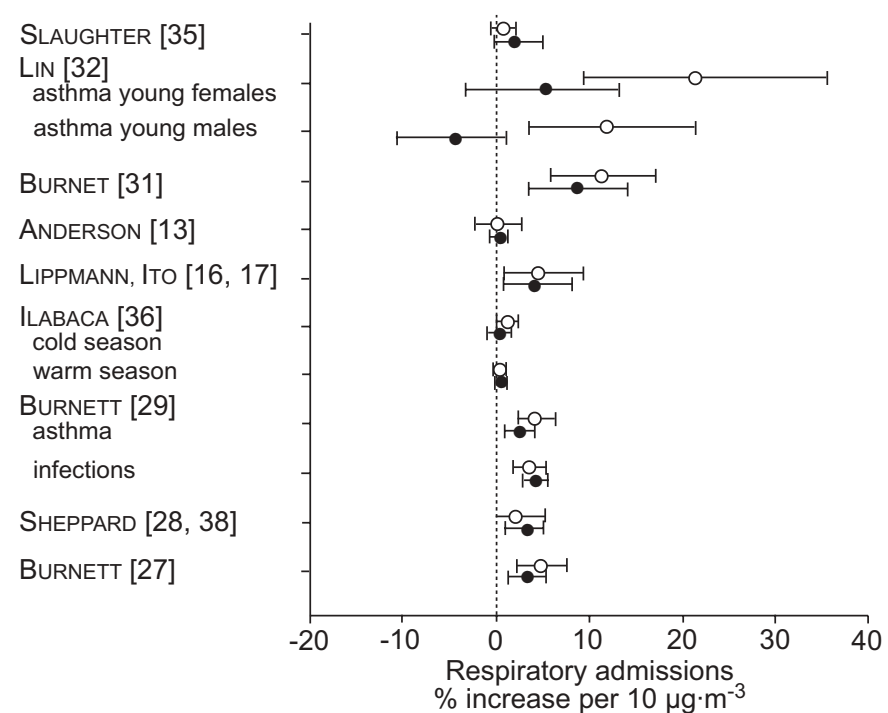

FIGURE 2. Effect of fine and coarse $(\bigcirc)$ particles on respiratory admissions in published time series studies.

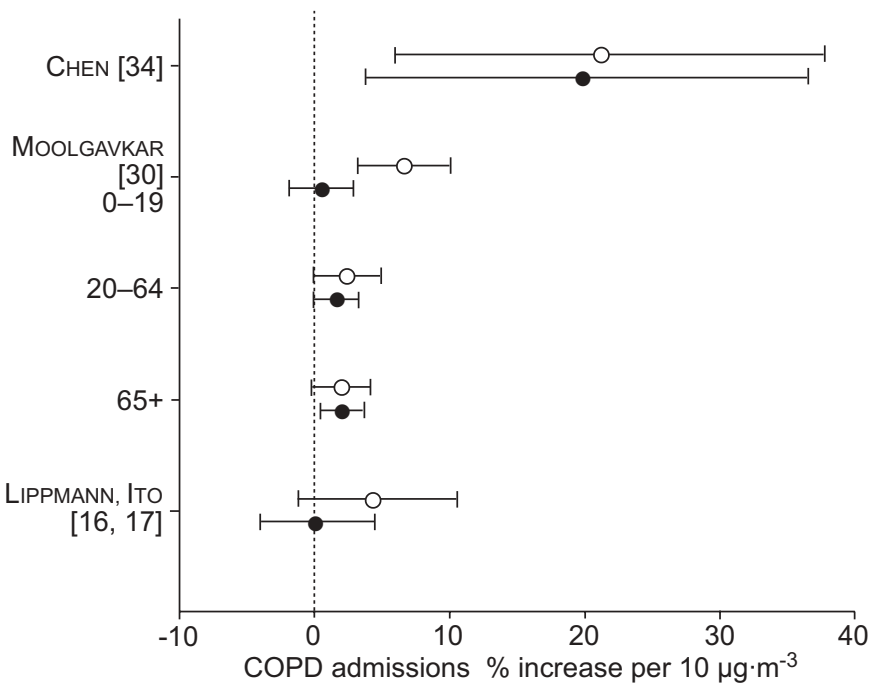

FIGURE 3. Effect of fine $(\bullet)$ and coarse $(\bigcirc)$ particles on chronic obstructive pulmonary disease (COPD) admissions in published time series studies.

PM10 is dominated by coarse crustal material, found significant effects of PM10 on outpatient visits for asthma, bronchitis and upper respiratory tract infections [41].

Another study from Washington State, USA, found a small increase in respiratory hospital admissions after dust storms where maximum $24 \mathrm{~h}$ PM10 concentrations exceeded 1,000 $\mu \mathrm{g} \cdot \mathrm{m}^{-3}$ [42]. Coefficients were estimated to be $\sim 3-4 \%$ per 100 $\mu \mathrm{g} \cdot \mathrm{m}^{-3}$, which is not very different from coefficients estimated from large time series studies on PM and hospital admissions.

In areas of Europe where roads are being sanded, and studded tires are being used in winter, episodes of high so called "spring dust" concentrations occur after the snow has melted. One study from Finland has addressed possible health

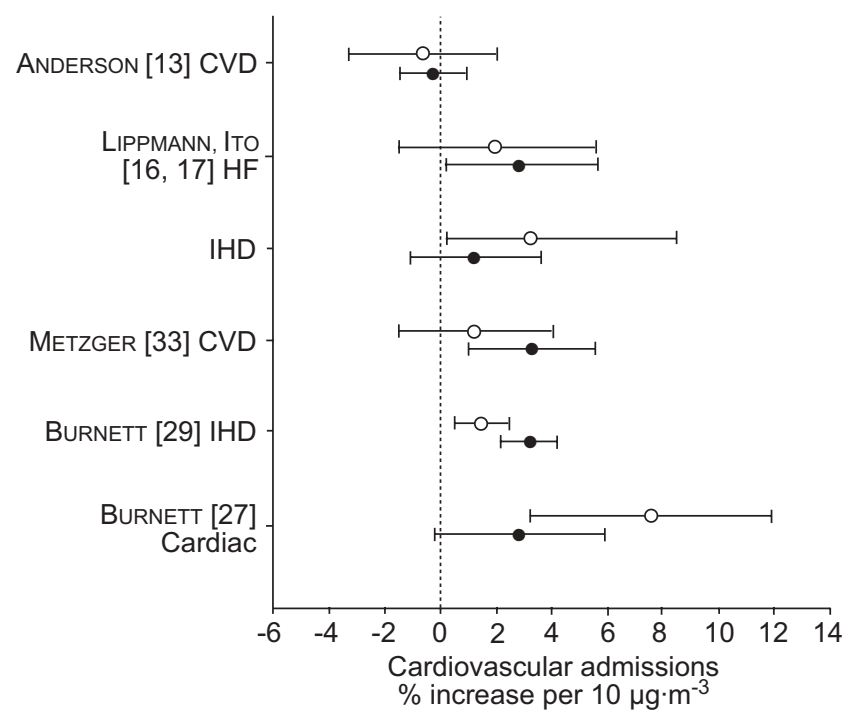

FIGURE 4. Effect of fine $(\bullet)$ and coarse $(\bigcirc)$ particles on cardiovascular admissions in published time series studies. CVD: cardiovascular disease; HF: heart failure; IHD: ischaemic heart disease.

consequences [43]. TSP, PM10 and PM2.5 were measured, and coarse mass was estimated by subtracting PM2.5 from PM10. Median concentrations were $57,28,15$ and $8 \mu \mathrm{g} \cdot \mathrm{m}^{-3}$ respectively, but maximum concentrations were 234, 122, 55 and 67 $\mu \mathrm{g} \cdot \mathrm{m}^{-3}$ ( $24 \mathrm{~h}$ average). Correlations between the different particle metrics were very high at $0.90-0.98$ in this study so that they could not be separated in the analysis. Morning peak flow and cough were found to be associated with all the particle metrics (except TSP which was not analysed) in a panel of asthmatic children. Because of the high correlations between metrics, no firm conclusions with respect to an independent role of coarse PM can be drawn. Two other studies from Finland found no evidence of coarse PM ("spring dust") effects on peak flow and symptoms in panels of asthma patients $[44,45]$.

\section{EFFECTS OF COARSE PARTICLES ON LONG-TERM MEASURES OF MORBIDITY}

Analyses conducted within the Children's Health Study in southern California found no evidence of an association between coarse PM and bronchitis symptoms in a prospective assessment of children with asthma [46]. In the same data, $\mathrm{NO}_{2}$ and organic carbon were the pollutants most closely associated with symptoms. The correlation between annual average PM2.5 and coarse particles was only 0.24, whereas PM10 was highly correlated with both at 0.79 . This analysis took into account both within and between community variations over a 4 -yr period. This illustrates that separate assessment of associations with fine and coarse PM is possible when both are actually measured. Earlier publications from this cohort found some evidence of an effect of coarse PM on lung function growth that was inseparable from effects of other particle metrics [47, 48]. However, in these analyses the within community variation in air pollution exposures over time was not taken into account, and correlations between PM10, coarse and fine particles were much higher for this reason than in the analysis of bronchitis symptoms among children. 
A study from eight districts in four cities in China reported that the prevalence of respiratory symptoms in children was more strongly associated with TSP, and with coarse than with fine particles. Mean concentrations were high at $356 \mu \mathrm{g} \cdot \mathrm{m}^{-3}$ for TSP, and 151, 92 and $59 \mu \mathrm{g} \cdot \mathrm{m}^{-3}$ for PM10, PM2.5 and coarse mass, respectively [49].

\section{SOME REMARKS ON THE TOXICOLOGY OF COARSE PARTICLES}

An important consideration when discussing the toxicology of coarse and fine particles is dosimetry. Few investigators have specifically addressed the particle lung doses from fine and coarse PM. VENKATARAMAN and KAO [50] showed that on a mass basis, the proportion of fine PM being deposited in the pulmonary region is three times larger than the proportion of coarse PM. The number dose to the pulmonary region, however, was five orders of magnitude higher for fine than for coarse PM. This indicates that if effects of PM are even partly related to particle number, the fine fraction completely dominates.

Most toxicology studies that investigated effects of coarse and fine PM to date have expressed results on a mass basis. SHI et al. [51] found higher hydroxyl radical generating capacity in coarse mode particles than in fine mode particles, especially when sampling was in winter. In contrast, the cytotoxicity of solventextractable organic compounds was found to be larger in fine than in coarse particles [52]. Another study found a greater haemolytic potential in fine than in coarse particles when expressed on a mass basis [53]. However, when expressed per particle surface area, effects were similar, suggesting that particle surface area may be an important determinant of particle effects on health. BECKER et al. [54] showed that cytokine production of macrophages was especially enhanced by coarse PM and by bacterial endotoxin content of coarse PM in particular. Another study by the same investigators found that human lung macrophages were more likely to be stimulated to produce inflammatory responses by coarse than by fine PM, again on a mass basis, and that this was related to bacterial endotoxin content [55]. It is likely that the chemical composition is driving toxicological effects, and for coarse PM it may vary a lot from place to place and also between seasons.

Taken together, these studies clearly show that coarse PM exerts toxic effects in laboratory experiments, and that such effects are at least as potent as those observed in experiments using fine PM, when expressed on a mass basis. However, when taking into consideration particle number or surface area, the pulmonary dose of toxic material related to fine PM may be so much larger than the dose related to coarse PM that for this reason alone, comparison on a mass basis may be less informative.

\section{CONCLUDING REMARKS ON THE HEALTH EFFECTS OF COARSE PARTICLES Mortality}

There is some evidence for effects of coarse PM on mortality. This is most prominent in studies from arid regions (Coachella Valley, Phoenix, USA) where coarse PM concentrations are relatively high. Studies from Mexico city, the Detroit area and from Canada also provide some support for an effect of coarse PM on mortality.
Few studies have analysed fine and coarse PM jointly. Three studies that did, showed that the effects of coarse PM were reduced to nonsignificance after adjustment for fine PM but the effects of fine PM remained after adjustment for coarse PM. A study from Mexico found the opposite. In Santiago coarse PM were more important than FP in summer. Coarse and fine PM are also likely to have differential associations with other (gaseous) pollutants, so that adjustment for such pollutants may also affect the results of statistical analyses. However, the present database does not allow assessment of this.

The correlation between fine and coarse PM in all of these studies was moderate at values $0.28-0.59$ with one higher value at 0.69 in Steubenville, USA [24]. In contrast, the correlations between PM10 and fine as well as coarse PM was much larger in all studies. Usually, correlations between PM10 and fine PM were largest, but there were some exceptions, notably from arid areas where PM10 was dominated by coarse PM. The implication is that analyses based on PM10 are generally unable to support statements on the relative importance of fine and coarse PM. The modest correlations between fine and coarse PM on the other hand do allow separation of the two effects. It is unfortunate that so far, few studies have reported the results of two-pollutant analyses.

There is only one report from Europe at this point. This study from the UK found no effect of either fine or coarse PM on mortality. However, in the warm season, significant effects of fine but not coarse PM were observed. The two USA cohort studies did not show a significant effect of spatial variations in coarse particles on mortality.

\section{Morbidity}

In studies of COPD, asthma and respiratory admissions coarse PM has a stronger or as strong short-term effect as fine PM. Some studies have found associations between respiratory morbidity endpoints and coarse particles in areas where no such associations with mortality were found. The available evidence suggests that the toxicological potential of coarse particles is sufficient to cause respiratory and cardiovascular morbidity that leads to increases in hospital admissions. Very few data exist that allow estimates of long-term effects of coarse PM on morbidity. One study from China, conducted at high levels of exposure, suggests that the prevalence of respiratory disease among children is especially associated with coarse PM. In contrast, the Children's Health Study from California found little evidence of long-term effects of coarse PM on morbidity.

\section{Exposure assessment}

One reason why it might be more difficult to address effects of coarse particles in epidemiological studies is that the spatial variation in coarse particles tends to be larger than in fine particles [56]. In arid region the spatial variability might be less. Also, the instrumental measurement error in coarse particle concentrations might be larger when the measurement is indirect, i.e. coarse PM concentrations result from a subtraction of measured PM2.5 from measured PM10 concentrations. In none of the reported epidemiological studies have these issues been dealt with explicitly. Only the report from the Coachella Valley study [18] reports on correlations between coarse and fine particles, respectively, measured at two 
different sites: for coarse particles, the correlation was 0.61 , for fine particles, 0.60 . Two other studies have provided some evidence. A recent study from Austria found higher spatial correlation for fine PM than for coarse PM in summer $(0.91$ versus 0.55$)$ but in the winter it was opposite ( 0.73 versus 0.84$)$ [57]. A study from the former German Democratic Republic (GDR) found high spatial correlations for both fine and coarse PM and for endotoxin in fine and coarse PM (0.85 versus 0.88 ) [58]. In this study, endotoxin in coarse PM was ten times higher than in fine PM which may explain some of the high toxicity of fine PM in toxicology studies noted earlier. These limited data do not support the view that the spatial correlation of coarse PM is much worse than fine PM, but further data on this are needed. In few of the published studies authors have tried to ascertain the independent effects of coarse and fine PM, by including them in the same statistical model. As discussed, the correlation between the two is usually sufficiently low to allow meaningful two-pollutant analyses. Future analyses need to take these fundamental exposure issues into account.

\section{Policy issues}

A large number of studies over the world have been identified by this systematic review to demonstrate adverse health effects by coarse particles. The health effects of this particle size fraction has to some extent been overlooked and now presents an important challenge to study further by epidemiological, toxicological and chemical approaches. The coarse particle fraction is also of importance in the regulatory process as well as for control measures.

\section{ACKNOWLEDGEMENTS}

R. Atkinson at St. George's Hospital and Medical School, London, UK, helped in selecting studies to be included in the morbidity analyses.

\section{REFERENCES}

1 Wilson WE, Su HH. Fine particles and coarse particles: concentration relationships relevant to epidemiologic studies. J Air Waste Manag Assoc 1997; 47: 1238-1249.

2 Claiborn CS, Finn D, Larson TV, Koenig JQ. Windblown dust contributes to high PM2.5 concentrations. J Air Waste Manag Assoc 2000; 50: 1440-1445.

3 Schwartz J, Dockery DW, Neas LM. Is daily mortality associated specifically with fine particles? J Air Waste Manag Assoc 1996; 46: 927-939.

4 Klemm RJ, Mason RM Jr, Heilig CM, Neas LM, Dockery DW. Is daily mortality associated specifically with fine particles? Data reconstruction and replication of analyses. J Air Waste Manag Assoc 2000; 50: 1215-1222.

5 Anderson HR, Atkinson RW, Peacock JL, Sweeting MJ, Marston M. Ambient particulate matter and health effects publication bias in studies of short-term associations. Epidemiology 2005; 16: 155-163.

6 Health Effects Institute, Special Report. Revised analyses of time-series studies of air pollution and health. 2003.

7 Cifuentes LA, Vega J, Kopfer K, Lave LB. Effect of the fine fraction of particulate matter versus the coarse mass and other pollutants on daily mortality in Santiago, Chile. J Air Waste Manag Assoc 2000; 50: 1287-1298.
8 Lipfert FW, Morris SC, Wyzga RE. Daily mortality in the Philadelphia metropolitan area and size-classified particulate matter. J Air Waste Manag Assoc 2000; 50: 1501-1513.

9 Burnett R, Goldberg MS. Size fractionated particulate mass and daily mortality in 8 Canadian cities. In: Health Effects Institute, Special Report. Revised analyses of time-series studies of air pollution and health. 2003; pp. 85-89.

10 Burnett RT, Brook J, Dann T, et al. Association between particulate- and gas-phase components of urban air pollution and daily mortality in eight Canadian cities. Inhal Toxicol 2000; 12: Suppl. 4, 15-39.

11 Fairley D. Daily mortality and air pollution in Santa Clara County, California: 1989-1996. Environ Health Perspect 1999; 107: 637-641.

12 Fairley D. Mortality and air pollution for Santa Clara County, California, 1989-1996. In: Health Effects Institute Special Report. Revised analyses of time-series studies of air pollution and health. 2003; pp. 97-106.

13 Anderson HR, Bremner SA, Atkinson RW, Harrison RM, Walters S. Particulate matter and daily mortality and hospital admissions in the west midlands conurbation of the United Kingdom: associations with fine and coarse particles, black smoke and sulphate. Occup Environ Med 2001; 58: 504-510.

14 Castillejos M, Borja-Aburto VH, Dockery DW, Gold DR, Loomis D. Airborne coarse particles and mortality. Inhal Toxicol 2000; 12: Suppl. 1, 61-72.

15 Villeneuve PJ, Burnett RT, Shi Y, et al. A time-series study of air pollution, socioeconomic status, and mortality in Vancouver, Canada. J Expo Anal Environ Epidemiol 2003; 13: 427-435.

16 Lippmann M, Ito K, Nadas A, Burnett RT. Association of particulate matter components with daily mortality and morbidity in urban populations. Res Rep Health Eff Inst 2003: 5-82.

17 Ito K. Association of particulate matter components with daily mortality and morbidity in Detroit, Michigan. In: Health Effects Institute, Special Report. Revised analyses of time-series studies of air pollution and health. 2003; pp. 143-156.

18 Ostro BD, Broadwin R, Lipsett MJ. Coarse and fine particles and daily mortality in the Coachella Valley, California: a follow-up study. J Expo Anal Environ Epidemiol 2000; 10: 412-419.

19 Ostro B, Broadwin R, Lipsett M. Coarse particles and daily mortality in Coachella Valley, California. In: Health Effects Institute, Special Report. Revised analyses of time-series studies of air pollution and health. 2003; pp. 199-204.

20 Klemm RJ, Mason RM Jr. Aerosol Research and Inhalation Epidemiological Study (ARIES): air quality and daily mortality statistical modelling- interim results. J Air Waste Manag Assoc 2000; 50: 1433-1439.

21 Mar TF, Norris GA, Koenig JQ, Larson TV. Associations between air pollution and mortality in Phoenix, 1995-1997. Environ Health Perspect 2000; 108: 347-353.

22 Mar TF, Norris GA, Larson TV, Wilson WE, Koenig JQ. Air pollution and cardiovascular mortality in Phoenix, 19951997. In: Health Effects Institute, Special Report. Revised analyses of time-series studies of air pollution and health. 2003; pp. 177-182. 
23 Pope CA 3rd, Burnett RT, Thun MJ, et al. Lung cancer, cardiopulmonary mortality, and long-term exposure to fine particulate air pollution. JAMA 2002; 287: 1132-1141.

24 Dockery DW, Pope CA. An association between air pollution and mortality in six U.S. cities. N Engl J Med 1993; 329: 1753-1759.

25 EPA. Air Quality Criteria for Particulate Matter Vol. II.http:/ / cfpub.epa.gov $/$ ncea $/ \mathrm{cfm} /$ recordisplay.cfm?PrintVersion $=$ True\&deid=87903; 2004. Date accessed: June 10 2005; Date updated: May 172005.

26 Thurston GD, Ito K, Hayes CG, Bates DV, Lippmann M. Respiratory hospital admissions and summertime haze air pollution in Toronto, Ontario: consideration of the role of acid aerosols. Environ Res 1994; 65: 271-290.

27 Burnett RT, Cakmak S, Brook JR, Krewski D. The role of particulate size and chemistry in the association between summertime ambient air pollution and hospitalization for cardiorespiratory diseases. Environ Health Perspect 1997; 105: 614-620.

28 Sheppard L, Levy D, Norris G, Larson TV, Koenig JQ. Effects of ambient air pollution on nonelderly asthma hospital admissions in Seattle, Washington, 1987-1994. Epidemiology 1999; 10: 23-30.

29 Burnett RT, Smith-Doiron M, Stieb D, Cakmak S, Brook JR. Effects of particulate and gaseous air pollution on cardiorespiratory hospitalizations. Arch Environ Health 1999; 54: 130-139.

30 Moolgavkar SH. Air pollution and hospital admissions for diseases of the circulatory system in three U.S. metropolitan areas. J Air Waste Manag Assoc 2000; 50: 1199-1206.

31 Burnett RT, Smith-Doiron M, Stieb D, et al. Association between ozone and hospitalization for acute respiratory diseases in children less than 2 years of age. Am J Epidemiol 2001; 153: 444-452.

32 Lin M, Chen Y, Burnett RT, Villeneuve PJ, Krewski D. The influence of ambient coarse particulate matter on asthma hospitalization in children: case-crossover and time-series analyses. Environ Health Perspect 2002; 110: 575-581.

33 Metzger KB, Tolbert PE, Klein M, et al. Ambient air pollution and cardiovascular emergency department visits. Epidemiology 2004; 15: 46-56.

34 Chen Y, Yang Q, Krewski D, Shi Y, Burnett RT, McGrail K. Influence of relatively low level of particulate air pollution on hospitalization for COPD in elderly people. Inhal Toxicol 2004; 16: 21-25.

35 Slaughter JC, Kim E, Sheppard L, Sullivan JH, Larson TV, Claiborn C. Association between particulate matter and emergency room visits, hospital admissions and mortality in Spokane, Washington. J Expo Anal Environ Epidemiol 2004.

36 Ilabaca M, Olaeta I, Campos E, Villaire J, Tellez-Rojo MM, Romieu I. Association between levels of fine particulate and emergency visits for pneumonia and other respiratory illnesses among children in Santiago, Chile. J Air Waste Manag Assoc 1999; 49: 154-163.

37 Tolbert PE, Klein M, Metzger KB, et al. Interim results of the study of particulates and health in Atlanta (SOPHIA). J Expo Anal Environ Epidemiol 2000; 10: 446-460.

38 Sheppard L. Ambient air pollution and non-elderly asthma hospital admissions in Seattle, Washington, 1987-1994. Health Effects Institute, Special Report. Revised analyses of time-series studies of air pollution and health 2003: 227-230.
39 Schwartz J, Norris G, Larson T, Sheppard L, Claiborne C, Koenig J. Episodes of high coarse particle concentrations are not associated with increased mortality. Environ Health Perspect 1999; 107: 339-342.

40 Schwartz J. Air pollution and hospital admissions for respiratory disease. Epidemiology 1996; 7: 20-28.

41 Gordian ME, Ozkaynak H, Xue J, Morris SS, Spengler JD. Particulate air pollution and respiratory disease in Anchorage, Alaska. Environ Health Perspect 1996; 104: 290-297.

42 Hefflin BJ, Jalaludin B, McClure E, et al. Surveillance for dust storms and respiratory diseases in Washington State, 1991. Arch Environ Health 1994; 49: 170-174.

43 Tiittanen P, Timonen KL, Ruuskanen J, Mirme A, Pekkanen J. Fine particulate air pollution, resuspended road dust and respiratory health among symptomatic children. Eur Respir J 1999; 13: 266-273.

44 Pekkanen J, Timonen KL, Ruuskanen J, Reponen A, Mirme A. Effects of ultrafine and fine particles in urban air on peak expiratory flow among children with asthmatic symptoms. Environ Res 1997; 74: 24-33.

45 Pentitinen P, Timonen KL, Tiitanen P, Mirme A, Ruuskanen J, Pekkanen J. Ultrafine particles in urban air and respiratory health among adult asthmatics. Eur Resp J 2001; 17: 428-435.

46 McConnell R, Berhane K, Gilliland F, et al. Prospective Study of Air Pollution and Bronchitic Symptoms in Children with Asthma. Am J Respir Crit Care Med 2003; 168: 790-797.

47 Gauderman WJ, Gilliland GF, Vora H, et al. Association between air pollution and lung function growth in southern California children: results from a second cohort. Am J Respir Crit Care Med 2002; 166: 76-84.

48 Gauderman WJ, McConnell R, Gilliland F, et al. Association between air pollution and lung function growth in southern California children. Am J Respir Crit Care Med 2000; 162: 1383-1390.

49 Zhang JJ, Hu W, Wei F, Wu G, Korn LR, Chapman RS. Children's respiratory morbidity prevalence in relation to air pollution in four Chinese cities. Environ Health Perspect 2002; 110: 961-967.

50 Venkataraman C, Kao AS. Comparison of particle lung doses from the fine and coarse fractions of urban PM-10 aerosols. Inhal Toxicol 1999; 11: 151-169.

51 Shi T, Knaapen AM, Begerow J, Birmili W, Borm PJ, Schins RP. Temporal variation of hydroxyl radical generation and 8-hydroxy-2'-deoxyguanosine formation by coarse and fine particulate matter. Occup Environ Med 2003; 60: 315-321.

52 Hsiao WL, Mo ZY, Fang M, Shi XM, Wang F. Cytotoxicity of $\operatorname{PM}(2.5)$ and $\operatorname{PM}(2.5-10)$ ambient air pollutants assessed by the MTT and the Comet assays. Mutat Res 2000; 471: 45-55.

53 Diociaiuti M, Balduzzi M, De Berardis B, et al. The two $\operatorname{PM}(2.5)$ (fine) and $\mathrm{PM}(2.5-10)$ (coarse) fractions: evidence of different biological activity. Environ Res 2001; 86: 254-262.

54 Becker S, Fenton MJ, Soukup JM. Involvement of microbial components and toll-like receptors 2 and 4 in cytokine responses to air pollution particles. Am J Respir Cell Mol Biol 2002; 27: 611-618. 
55 Becker S, Soukup JM, Sioutas C, Cassee FR. Response of human alveolar macrophages to ultrafine, fine, and coarse urban air pollution particles. Exp Lung Res 2003; 29: 29-44.

56 Monn C. Exposure assessment of air pollutants: a review on spatial heterogeneity and indoor/outdoor/personal exposure to suspended particulate matter, nitrogen dioxide and ozone. Atmos Environ 2001; 35: 1-32.
57 Berner A, Galambos Z, Ctyroky C, et al. On the correlation of atmospheric aerosol components of mass size distributions in the larger region of a central European city. Atmosf Environ 2004; 38: 3959-3970.

58 Heinrich J, Pitz M, Bischof W, Krug N, Borm PJA. Endotoxin in fine (PM2.5) and coarse (PM2.5-10) particle mass of ambient aerosols. A temporo-spatial analysis. Atmosf Environ 2003; 37: 3659-3667. 